\title{
Quality and Brands of Amoxicillin Formulations in Nairobi, Kenya
}

\author{
Lilian C. Koech $\mathbb{D}^{1,2}$ Beatrice N. Irungu, ${ }^{2}$ Margaret M. Ng'ang'a, ${ }^{1}$ Joyce M. Ondicho, ${ }^{2}$ \\ and Lucia K. Keter ${ }^{2}$ \\ ${ }^{1}$ Department of Chemistry, School of Pure and Applied Sciences, Kenyatta University, P.O. Box 43844-00100, Nairobi, Kenya \\ ${ }^{2}$ Center for Traditional Medicine and Drug Research, Kenya Medical Research Institute, P.O. Box 54840-00200, Nairobi, Kenya \\ Correspondence should be addressed to Lilian C. Koech; lilkosh77@gmail.com
}

Received 12 August 2019; Accepted 4 January 2020; Published 13 June 2020

Academic Editor: Andrea Masotti

Copyright () 2020 Lilian C. Koech et al. This is an open access article distributed under the Creative Commons Attribution License, which permits unrestricted use, distribution, and reproduction in any medium, provided the original work is properly cited.

\begin{abstract}
Antibiotics are among the most counterfeited anti-infectious medicines in developing countries. Amoxicillin is one of the commonly prescribed, affordable, and easily accessible antibiotic in Kenya. It is a broad-spectrum antibiotic hence commonly used in chemotherapy. This study sought to determine the quality and identify the various brands of amoxicillin and its combination amoxicillin/clavulanic acid marketed in Nairobi County. Nairobi is the capital city of Kenya, gateway for imports and exports, and the headquarters to most of the pharmaceutical distributors. Ten wards in Nairobi County representing different socioeconomic settings were purposively sampled for the study. A detailed questionnaire was used to collect background data on brands of amoxicillin and amoxicillin/clavulanic acid in the market. A total of 106 different brands were found in the market: 85 were imports while 21 were locally manufactured. Fifty-three samples were analyzed with reference to the United States Pharmacopoeia. Amoxicillin and clavulanic acid contents for oral suspensions were determined immediately after reconstitution and 7 days thereafter to determine their stability during the prescription period. On day seven, $23.1 \%$ ( 3 out of 13) of amoxicillin and $66.7 \%$ (8 out of 12) amoxicillin/clavulanic acid oral suspensions presented levels below recommended limits. Uniformity of weight for amoxicillin capsules noted 13.6\% (3 out of 22) failure rate, while amoxicillin/clavulanic acid tablets complied. Potency determination for all amoxicillin capsules analyzed were within required limits, but amoxicillin/clavulanic acid tablets showed $33.3 \%$ (2 out of 6 ) noncompliance. For amoxicillin capsule and amoxicillin/clavulanic acid tablet dissolution tests, there was $10.5 \%$ (2 out of 19) and 50\% (2 out of 4) noncompliance, respectively. Overall, $37.7 \%$ of the drugs analyzed failed to comply with the Pharmacopoeia. These results highlight the presence of poor-quality amoxicillin formulations in Nairobi County, affirming the need for regular postmarket surveillance to inform on the situation of antibiotic quality in the Kenyan market.
\end{abstract}

\section{Introduction}

Over the past decade, increased public awareness on drug quality has been assessed in terms of counterfeit and/or substandard products [1]. According to the United States Food and Drug Administration (FDA), 50\% of medicines being sold in Africa are thought to be counterfeit and/or substandard $[2,3]$. Studies have reported anti-infectious agents, particularly antibiotics and antiparasitics, being highly predisposed to compromised quality especially in developing countries due to their high demand $[4,5]$. Orally administered anti-infective formulations accounted for $77 \%$; thus, they are the most counterfeited antibiotic medicines [6].
Efforts to conduct studies on the quality of drugs in the Kenyan market have been reported since the early 1980s. According to reports by the Kenya National Quality Control Laboratory (NQCL), the failure rate for antibiotics was reported at $24.3 \%$ in the year $1996-2001,9.4 \%$ in 2004 2005 , and $17.3 \%$ in $2006-2007$ [7].

Amoxicillin is an antibiotic that belongs to a class of drugs called penicillin, which fall in the beta-lactam family of antibiotics [8]. $\beta$-Lactam utilization accounts for $65 \%$ of the total global antibiotic market [9], because they work extremely well against a wide variety of bacteria while exerting little toxicity towards mammalian cells [10]. Amoxicillin is predisposed to degradation by beta-lactamase-producing 
bacteria; thus, it may be administered with clavulanic acid, a $\beta$-lactamase inhibitor [11]. The combination is used as a broad-spectrum antibiotic for the treatment of a wide range of bacterial infections, including upper and lower respiratory tract infections and infections of the skin and soft tissue [12].

In Kenya, the magnitude of substandard and/or counterfeit antibiotics is unknown, yet the issue of poor-quality drugs is extensively discussed in the media and respective ministries ([13-15]; [16-19]). There have been few studies in which the quality of amoxicillin has been analyzed in Kenya [20-22] all of which reported the presence of poor quality but none in a scope that informs on the situation in our Kenyan market. As a consequence, there is a need for information on the quality of such commonly prescribed antibiotics to create awareness for public information. For that reason, the aim of this study was to identify the various brands and determine the quality of amoxicillin formulations marketed to the public within Nairobi County.

\section{Materials and Methods}

2.1. Study Location. This study was undertaken in Nairobi County, the capital city of Kenya and home to the largest airport in East Africa serving as the gateway for imports and exports, thus making it the commercial hub of the country. In addition, it is the headquarters of most of the pharmaceutical distributors and wholesalers in the country $[23,24]$. Nairobi has seventeen subcounties which are further divided into eighty-five wards. It has a population of about 3 million people contributing to $8.1 \%$ of the Kenyan population, hence it is the most populous county in the country [25]. Figure 1 displays the Nairobi County map with the study wards indicated.

2.2. Study Design. This was a cross-sectional study to identify brands and quality of amoxicillin formulations from retail and private hospital pharmacies in different locations within the county. The locations were selected based on economic stratification: upper-, middle-, and lower-income classes $[27,28]$. The wards with an upper-income population included Westlands/Kangemi and Karen; middle-income population wards were South B and South C; middlelower-income populations included Zimmerman and Kasarani; while lower-income population wards were Kibra, Kayole, and Umoja (Figure 1).

A market surveillance was first undertaken in the 10 wards in the county to identify the various brands of amoxicillin and amoxicillin/clavulanic acid drugs in March and April of 2016. This was achieved by use of a data capture form with open-ended questions administered by trained research assistants. Additional information such as manufacturer and country of origin were also captured. Personnelin-charge of the facility were informed of the nature of the study and assured of confidentiality before data collection or drug sampling.

According to the Pharmacy and Poisons Board-Kenya register of 2015, 998 pharmacies were registered in Nairobi (http://www.Pharmacyboardkenya.org/?p=530). Using the Krejcie and Morgan sample table [29], 284 retail and private hospital pharmacies were visited to identify the various brands of amoxicillin and amoxicillin/clavulanic acid drugs but only 278 responded ( $98 \%$ response rate).

Thereafter, samples were purchased for analysis from 168 out of 177 (95\% response rate) retail and private hospital pharmacies located in these wards selected through purposive sampling. In each retail and private hospital pharmacies sampled, all the amoxicillin and amoxicillin/clavulanic acid brands stocked were sampled to eliminate bias. A total of 148 samples were sampled between April and July 2016 which formed the primary samples. Subsequently, secondary sampling was carried out purposively by eliminating brands with similar batch numbers from the same wards, while unique brands were given priority to achieve a sample size of 53. These consisted of 6 amoxicillin/clavulanic acid tablets, 22 amoxicillin capsules, and 13 amoxicillin and 12 amoxicillin/clavulanic acid dry oral suspensions. Two controls of the innovator drugs, an amoxicillin/clavulanic acid tablet with a strength of $625 \mathrm{mg}$ and an amoxicillin oral dry suspension with a strength of $250 \mathrm{mg} / 5 \mathrm{ml}$, were sourced from one of the official local distributors. The samples were assigned unique codes based on study location.

2.3. Chemicals and Reagents. Amoxicillin trihydrate standard ( $w / w 99.95 \%)$ and clavulanate potassium standard (92.75\%) from Medopharm Private Limited (Guduvanchery, India) were generous gifts from Dawa Limited and National Quality Control Laboratory (NQCL), respectively. Potassium dihydrogen phosphate (Sigma Aldrich Chemical Co. Ltd., Gillingham, Dorset, UK) and phosphoric acid (Merck Pvt. Ltd., Guateng, South Africa) were of analytical grade. Acetonitrile (Sigma-Aldrich Co. Steinheim, Germany) and methanol (Thermo Fischer Scientific UK Ltd., Loughborough, UK) were of HPLC grade solvents.

2.4. Equipment and Materials. The liquid chromatographic system consisted of an Agilent 1200 Infinity series highperformance liquid chromatography (LC) system (Agilent Technologies, Deutschland, Germany) supported by OpenLAB software version A.01.03 and equipped with a G1314B Agilent 1260 Infinity Variable Wavelength UV Detector. The temperature was controlled using a G1316A column oven with a G1330B Agilent 1260 Infinity Thermostatted Column Compartment. The LC system also had a G1311C Agilent 1260 Infinity Quaternary Pump and a G1329B Autosampler. A dissolution tester (DS 800, Lab India, Pvt. Ltd., Mumbai, India) was used in the study. A double-beam T90+ UV/Vis spectrophotometer supported by the UVWIN software version 5.2.0 (PG Instruments Ltd., Leicestershire, United Kingdom) and quartz cuvettes with a path length of $1 \mathrm{~cm}$ were used.

A Barnstead Smart2Pure ${ }^{\mathrm{TM}}$ water purification system (Thermo Fisher Scientific, Massachusetts, United States) was used to obtain ultrapure water. A Shimadzu AUW220D semi-micro-analytical electronic weighing balance (Shimadzu Corporation, Kyoto, Japan) with a sensitivity of $\pm 0.1 \mathrm{mg}$ was used for weighing. All the mobile phase preparations were degassed using a MRC DC-200H Ultrasonic Cleaner (MRC Lab Ltd., Holon, Israel). 


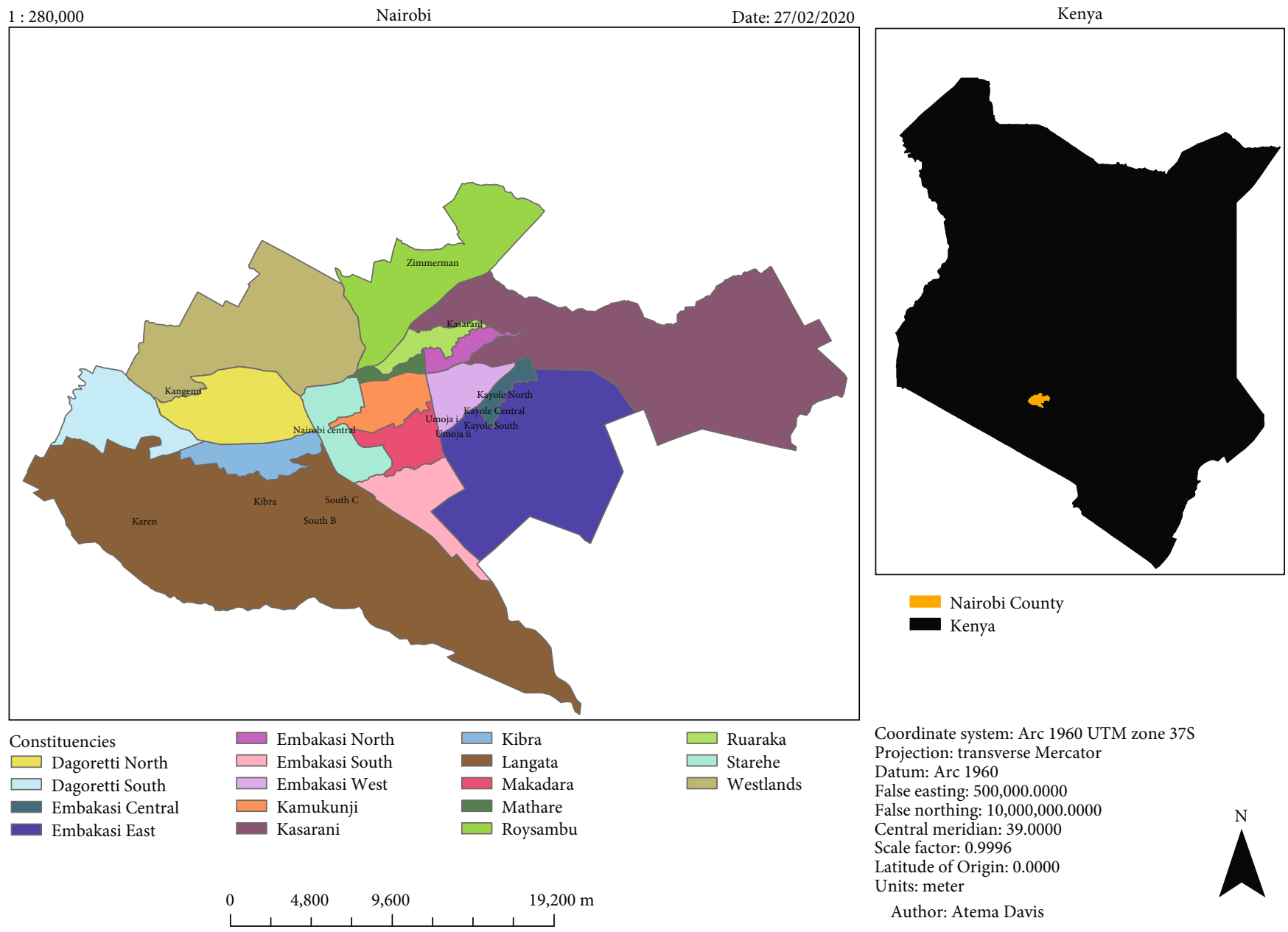

FIGURE 1: Nairobi County map showing the location of the selected wards [26].

2.5. Determination of Uniformity of Weight. Uniformity of weight determination was carried out for 28 solid dosage preparations (tablets and capsules samples) plus a control to check for consistency in weight of dosage units. Twenty units from each of the solid dosage formulations and the control were taken at random and then weighed. The content of each of the 20 weighed tablets and capsules from the respective samples were separately homogenized, labelled, and stored in air-tight amber containers for content determination. Average weights and percentage deviations from the mean values were calculated for each sample and control.

2.6. Potency Determination. The determination of amoxicillin and clavulanic potency was performed according to criteria established by the USP [30]. The percentage label claim (\% L.C.) of each drug sample was obtained by comparing the average peak areas and concentrations of both the standard and sample solutions putting into account the average weight in case of tablet or capsule contents, the purity of the standard, and the label claim contents of each sample.

2.6.1. System Suitability Test (SST). System suitability test was performed routinely before sample analysis could commence. It is undertaken to verify resolution, column efficiency and repeatability of a chromatographic system to guarantee its competence for a particular analysis [31]. Content assay of the active pharmaceutical ingredients (API), dissolution testing, and impurity determinations must pass a set of predefined acceptance criteria (Table 1), hence an integral part of any analytical procedure [32].

2.6.2. Mobile Phase System. The mobile phase solution for amoxicillin capsules and oral dry suspensions consisted of acetonitrile and 0.05 moles potassium dihydrogen phosphate buffer $\mathrm{pH} 5.0(1: 24, v / v)$. The $\mathrm{pH}$ was adjusted using potassium hydroxide solution $(45 \% w / w)$. The mobile phase for amoxicillin/clavulanic acid tablets and oral suspensions consisted of acetonitrile and 0.057 moles potassium dihydrogen phosphate buffer pH5.0 $(1: 19, v / v)$. The $\mathrm{pH}$ was adjusted using phosphoric acid. The buffers were filtered through $0.45 \mu \mathrm{m}$ nylon filters and degassed before use.

2.6.3. Amoxicillin Capsule Sample Preparation. The homogenized contents of each sample stored in air tight amber containers were weighed. A quantity of about the average weight obtained from a uniformity of weight test done earlier was weighed accurately in triplicates for each sample. Only 
TABLE 1: Method SST compared to acceptance limits parameters as per USP.

\begin{tabular}{|c|c|c|c|}
\hline \multirow{2}{*}{ Parameter } & \multicolumn{2}{|c|}{ Actual method suitability parameters } & \multirow{2}{*}{ Acceptable criteria (USP) } \\
\hline & Amoxicillin & Clavulanic acid & \\
\hline Precision/injection repeatability & \multicolumn{2}{|c|}{$\begin{array}{l}\text { Indicated in the data for respective samples } \\
\text { in the result tables }\end{array}$} & Relative standard deviation $\leq 2 \%$ \\
\hline Resolution factor $(R)$ & \multicolumn{2}{|c|}{2.76 to 3.17} & $R>1.5$ \\
\hline Tailing factor $(T)$ & 0.89 to 1.52 & 0.99 to 1.6 & $T \leq 2$ \\
\hline Theoretical plates $(N)$ & $2017-2470$ & $3970-4480$ & $N \geq 2000$ plates \\
\hline
\end{tabular}

samples that complied with the compendia specification for uniformity of weight were subjected to API determination.

2.6.4. API Determination. The samples were either in $250 \mathrm{mg}$ or $500 \mathrm{mg}$ strength. Each sample was weighed into $200 \mathrm{ml}$ volumetric flasks and topped to mark with the buffer. The solutions were sonicated for 10 minutes. Aliquots of $20 \mathrm{ml}$ for $250 \mathrm{mg}$ and $10 \mathrm{ml}$ for $500 \mathrm{mg}$ of the resulting solutions were pipetted into $25 \mathrm{ml}$ volumetric flasks and made to mark with the buffer, obtaining the concentration of approximately $1 \mathrm{mg} / \mathrm{ml}$. The solution was filtered through a $0.45 \mu \mathrm{m}$ syringe-adaptable membrane filter into LC amber vials and analyzed. Each of the replicates was injected three times.

2.6.5. Amoxicillin Dry Oral Suspension Sample Preparation. A total of thirteen samples with strengths of $125 \mathrm{mg} / 5 \mathrm{ml}$ and $250 \mathrm{mg} / 5 \mathrm{ml}$ and control $(250 \mathrm{mg} / 5 \mathrm{ml})$ were reconstituted with ultrapure water to the mark as specified on the labeling and thoroughly mixed by shaking. Aliquots of $8 \mathrm{ml}$ $(125 \mathrm{mg} / 5 \mathrm{ml})$ and $4 \mathrm{ml}(250 \mathrm{mg} / 5 \mathrm{ml})$ were accurately taken in three replicates using analytical volumetric pipettes into $200 \mathrm{ml}$ volumetric flasks and topped up to volume with the mobile phase. The solutions were sonicated for 10 minutes; obtaining the concentration of approximately $1 \mathrm{mg} / \mathrm{ml}$. The solutions were filtered using a $0.45 \mu \mathrm{m}$ membrane filter into LC amber vials and analyzed. Each of the replicates was injected three times. The samples and control were analyzed on the day they were reconstituted (day zero) and on the seventh day after reconstitution to determine their stability. The samples were stored at room temperature $\left(25 \pm 1^{\circ} \mathrm{C}\right)$ after reconstitution.

2.6.6. Amoxicillin Standard Preparation. Amoxicillin standard was prepared as per the compendia method [30]. Approximately $12 \mathrm{mg}$ of amoxicillin trihydrate with a standard potency of $99.95 \%$ was accurately weighed in two replicates $\mathrm{A}$ and $\mathrm{B}$ into a $10 \mathrm{ml}$ volumetric flasks, dissolved and made to volume with the buffer solution, obtaining the concentration of about $1.2 \mathrm{mg} / \mathrm{ml}$. The solution was sonicated for 7 minutes and filtered through a $0.45 \mu \mathrm{m}$ membrane filter into LC amber vials and analyzed. Each of the replicates was injected three times.

2.6.7. Amoxicillin/Clavulanic Acid Tablet Sample Preparation. Twenty tablets of each of the 6 samples of tablets and the control were crushed into fine powder with a pestle and mortar. The weight equivalent to the average weight for each sample were accurately weighed. The tablets had strengths of
$375 \mathrm{mg}$ and $625 \mathrm{mg}$ and control (625 mg). Each sample and control were weighed in three replicates into $100 \mathrm{ml}$ volumetric flasks, dissolved in and made to volume with the buffer. The solutions were sonicated for 10 minutes. Aliquots of $7 \mathrm{ml}(375 \mathrm{mg})$ and $4 \mathrm{ml}(625 \mathrm{mg})$ of the resulting solutions were pipetted into $50 \mathrm{ml}$ volumetric flasks and made to the mark with the buffer, obtaining a concentration of approximately $0.5 \mathrm{mg} / \mathrm{ml}$. The solutions were filtered through a $0.45 \mu \mathrm{m}$ membrane filter into LC amber vials and analyzed. Each of the replicates was injected three times.

2.6.8. Amoxicillin/Clavulanic Acid Dry Oral Suspension Sample Preparation. Twelve samples of amoxicillin/clavulanic acid dry oral suspension samples (with strengths of $228.5 \mathrm{mg} / 5 \mathrm{ml}, 457 \mathrm{mg} / 5 \mathrm{ml}$, and $642.9 \mathrm{mg} / 5 \mathrm{ml}$ ) were all reconstituted with ultrapure water to the mark as specified in the labeling, thoroughly mixed, and freed of air bubbles. Three replicate volumes of $4 \mathrm{ml}(642.9 \mathrm{mg} / 5 \mathrm{ml})$ were then taken using analytical volumetric pipettes into $200 \mathrm{ml}$ volumetric flasks and accurately topped up with the buffer. The solution was sonicated for 10 minutes. This made a stock solution from which aliquots of $4 \mathrm{ml}$ were transferred into a $20 \mathrm{ml}$ volumetric flask and made to mark with the buffer to make the final concentration of approximately $0.5 \mathrm{mg} / \mathrm{ml}$. The same procedure was repeated for $228.5 \mathrm{mg} / 5 \mathrm{ml}$ and $457 \mathrm{mg} / 5 \mathrm{ml}$ where three replicate aliquots of $3 \mathrm{ml}$ each were transferred into $100 \mathrm{ml}$ and $200 \mathrm{ml}$ volumetric flasks, respectively. This made a stock from which $4 \mathrm{ml}$ was taken into a $10 \mathrm{ml}$ volumetric flask to make the final concentration of about $0.5 \mathrm{mg} / \mathrm{ml}$. The samples were analyzed on the day they were reconstituted and on day 7 after reconstitution to determine their stability. The solution was filtered through a $0.45 \mu \mathrm{m}$ membrane filter into LC amber vials and analyzed. Each of the replicates was injected three times. The samples were stored at room temperature $\left(25 \pm 1^{\circ} \mathrm{C}\right)$ after reconstitution.

2.6.9. Amoxicillin and Clavulanic Acid Standard Preparation. As per the monograph [30], approximately $25 \mathrm{mg}$ of amoxicillin trihydrate with a standard potency of $99.95 \%$ and $10 \mathrm{mg}$ of clavulanate lithium with a potency of $96.4 \%$ were weighed (mixed) in two replicates A and B to a $50 \mathrm{ml}$ volumetric flask. This was dissolved in ultrapure water and topped up to the $50 \mathrm{ml}$ mark to produce a final concentration of approximately $0.5 \mathrm{mg} / \mathrm{ml}$ of amoxicillin and $0.2 \mathrm{mg} / \mathrm{ml}$ of clavulanate lithium. The solution was filtered through a 
$0.45 \mu \mathrm{m}$ membrane filter into LC amber vials and analyzed. Each of the replicates was injected three times.

2.6.10. Chromatographic System for Content Determination. The chromatograph wavelength was set at $220 \mathrm{~nm}$ and separation was achieved from Symmetry ${ }^{\circledR}$ C18, $5 \mu \mathrm{m}, 250 \times 4 \mathrm{~mm}$ column (Waters Corp., Massachusetts, USA) maintained at $40 \pm 1^{\circ} \mathrm{C}$ in a thermostat oven. The injection volume was set at $10.0 \mu \mathrm{l}$ and the flow rate at $1.50 \mathrm{ml} / \mathrm{min}$.

2.7. Dissolution Studies. Dissolution studies were undertaken for solid dosage preparations according to the USP [30]. Dissolution station apparatus was set to $37^{\circ} \mathrm{C} \pm 0.5^{\circ} \mathrm{C}$ for 30 minutes and a frequency of 75 rotations per minute (rpm). A set volume of $900 \mathrm{ml}$ of dissolution medium (distilled water) was accurately measured using a $1000 \mathrm{ml}$ measuring cylinder and poured into each of the six glass vessels and maintained at the set temperature. Standard thermometers were placed in each vessel to crosscheck the temperature. Only samples that complied with the standard requirement for API were subjected to the dissolution studies. These comprised of 19 samples of amoxicillin capsules, 4 samples of amoxicillin/clavulanic acid tablets, and the control. Six from every sample and control were placed into the six dissolution glass vessels. At the end of the run time, aliquots of $20 \mathrm{ml}$ were taken from each vessel. The drug solutions were allowed to equilibrate to room temperature and portions filtered.

Amoxicillin/clavulanic acid tablet aliquots were transferred into amber vials and analyzed using LC with Symmetry ${ }^{\circledR} \mathrm{C} 18$, $250 \times 4 \mathrm{~mm}, 5 \mu \mathrm{m}$ column (Waters Corp., Massachusetts, USA) maintained at $40^{\circ} \mathrm{C}$ in a thermostat oven; wavelength was set at $220 \mathrm{~nm}$. The mobile phase consisted of acetonitrile and potassium hydrogen phosphate buffer pH $5.0(1: 24 \mathrm{v} / \mathrm{v})$ at a flow rate of $2.0 \mathrm{ml} / \mathrm{min}$. The injection volumes were $20 \mu \mathrm{l}$ and were made in triplicates.

For amoxicillin samples, the aliquots obtained formed the stock solution from which $10 \mathrm{ml}$ (for $250 \mathrm{mg}$ sample strength) and $5 \mathrm{ml}$ (for $500 \mathrm{mg}$ sample strength) for amoxicillin capsules were accurately transferred into a $25 \mathrm{ml}$ volumetric flask and made to mark with ultrapure water and analyzed using a UV/Vis spectrophotometer at $272 \mathrm{~nm}$ against amoxicillin trihydrate standard with a concentration of $0.1 \mathrm{mg} / \mathrm{ml}$.

2.8. Statistical Analysis. All results were recorded as the mean values \pm SD of at least three replicates for each by using Statistical Package for Social Scientists (SPSS) software version 21.0 and Excel MS 2016.

2.9. Ethical Approval. Ethical approval was obtained from the Kenya Medical Research Institute Scientific and Ethics Review Committee (SERU) (KEMRI/SERU/CTMDR/012/3059). Amoxicillin and amoxicillin/clavulanic acid are prescriptiononly drugs, hence an authorization letter from the Kenya Medical Research Institute allowing for the purchase of the samples was presented.

\section{Results}

3.1. Brand Frequency and Countries of Origin of Amoxicillin and Amoxicillin/Clavulanic Acid in the Market. Out of 278 pharmacies that responded, 99.6\% (277) stocked amoxicillin and amoxicillin/clavulanic acid products. A total of 106 different brands were found in the market, among which 52 were single-molecule amoxicillin imports while 33 were amoxicillin/clavulanic acid combination imports. Locally manufactured brands accounted for 21 of the brands recorded and were all single-molecule amoxicillin products. This study further established that all (100\%) of the amoxicillin/clavulanic acid drugs found in Nairobi market were imported. More than half $(72.6 \%)$ of the pharmacies visited stocked the innovator brands for both single-molecule formulations $\left(\right.$ Amoxil $\left.^{\circledR}\right)$ and amoxicillin/clavulanic acid combination (Augmentin ${ }^{\circledR}$ ). Amoxil $^{\circledR}$ accounted for $19.3 \%$ of all amoxicillin samples recorded in the sampled locations while Augmentin ${ }^{\circledR}$ was $15.9 \%$ as shown in Figure 2. Innovator brands Amoxil ${ }^{\circledR}$ and Augmentin ${ }^{\circledR}$ were predominantly stocked in Nairobi Central (28.2\%), a location that serves all income classes and in the high- and middle-income areas; $14.4 \%$ being in Westlands, $10.4 \%$ in Karen, $7.7 \%$ in South C, and $9.3 \%$ in South B. In lower-income populations, $4.5 \%$ were stocked in Kibra and $6.2 \%$ in Kayole, while in middle-lower-income populations, $6.0 \%$ were in Zimmerman and $7.2 \%$ in Kasarani. The most commonly stocked generics for amoxicillin and amoxicillin/clavulanic acid formulations were Penamox ${ }^{\circledR}$ (7.7\%) and Clavulin ${ }^{\circledR}(8.5 \%)$, respectively.

Generally, Nairobi Central had the highest frequency of amoxicillin drugs stocked in pharmacies at $25.7 \%$ as shown in Figure 3, followed by Westlands at 13.5\%. Pharmacies in the South $\mathrm{C}$ area had the lowest number of amoxicillin products stocked at $3.6 \%$.

Majority (85.2\%) of amoxicillin brands were imports with $43.9 \%$ being imported generic products, while $41.3 \%$ were innovator imported brands (Amoxil ${ }^{\circledR}$ and Augmentin ${ }^{\circledR}$ ). Innovator brands were mainly from the United Kingdom (25.5\%), France $(8.6 \%)$, and Belgium (6.9\%), while generic import products were predominantly from India (27.4\%), Canada (6.4\%), and China (2.4\%). Others products were from Egypt (2.2\%), United States (1.5\%), Pakistan (1.0\%), Germany $(0.55 \%)$, Turkey $(0.7 \%)$, Austria $(0.4 \%)$, Mexico $(0.32 \%)$, South Africa (0.3\%), Lebanon (0.14\%), Thailand (0.14\%), Indonesia $(0.14 \%)$, Philippines $(0.09 \%)$, Malaysia $(0.09 \%)$, Switzerland (0.05\%), Cyprus (0.05\%), Algeria (0.05\%), and Argentina $(0.05 \%)$. Locally manufactured amoxicillin products accounted for $14.8 \%$ of the brands found in the market.

3.2. Uniformity of Weight Determination. All the amoxicillin/clavulanic acid samples and control were within the acceptable uniformity of weight limits [32] as shown in Table 2.

Table 3 shows that $86.4 \%$ ( 19 out of 22 ) of the amoxicillin capsule samples complied with the USP compendia specifications for uniformity of weight [32]. According to the USP specifications, not more than two of the individual masses should deviate from the average mass of the percentage weight deviation, and none should deviate more than twice that percentage weight [32]. It was noted that the samples that failed were imported products and were eliminated from assay determination and dissolution tests. 


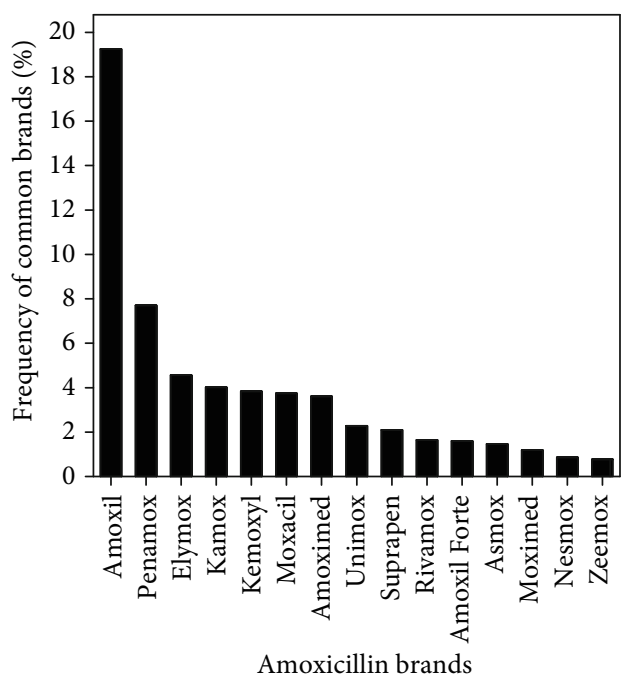

(a)

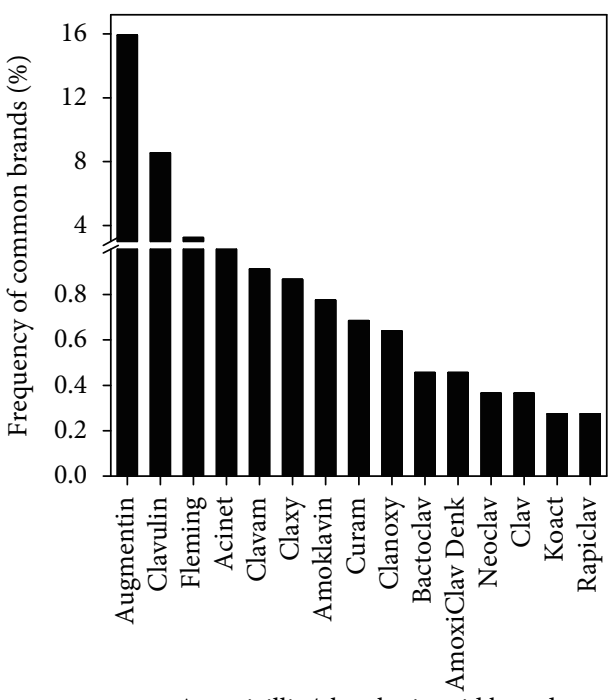

Amoxicillin/clavulanic acid brands

(b)

Figure 2: Predominant brands of amoxicillin (a) and amoxicillin/clavulanic acid (b) drugs stocked within Nairobi County.

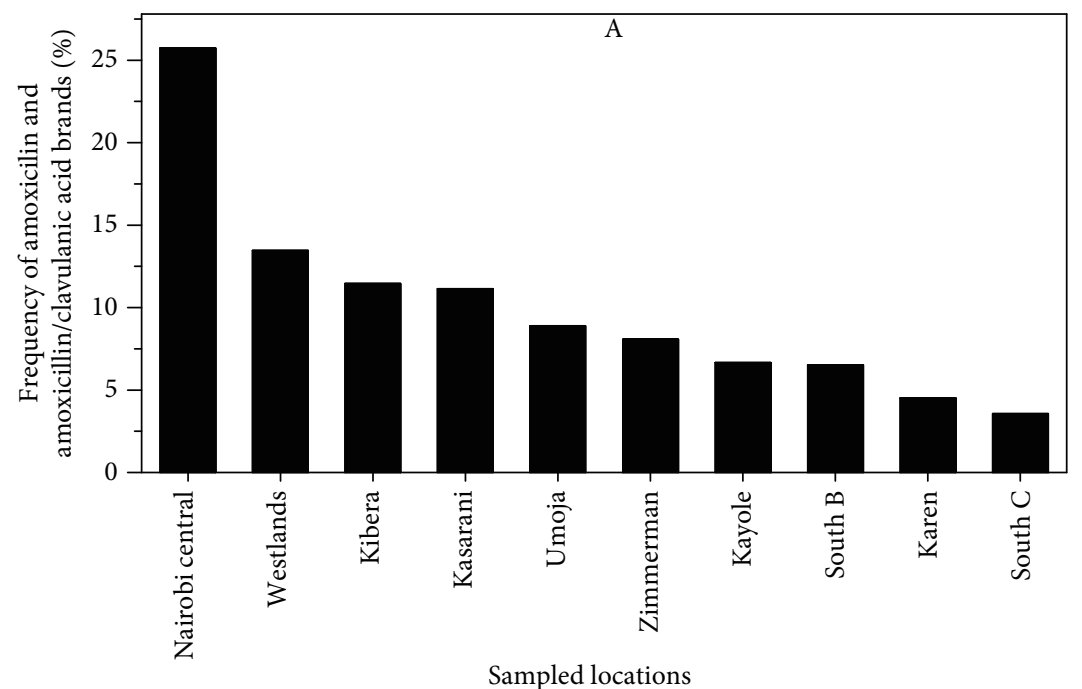

FIGURE 3: Frequency of amoxicillin and amoxicillin/clavulanic acid brands available in sampled wards within Nairobi County, Kenya.

\subsection{Potency Determination for Oral Dry Suspensions}

3.3.1. System Suitability Parameters (SST) and Active Ingredient Identification. The chromatographic system parameters were within the USP limits as given in Table 1.

Active ingredient identification test was first undertaken to ascertain that the samples contained the targeted API using HPLC as per the USP method [30]. The retention times of major peaks of all amoxicillin and amoxicillin/clavulanic acid samples corresponded to that of the reference standards. The retention time for amoxicillin samples and the standard was at $2.8 \pm 0.2$ minutes. Similarly, that of combination molecule; amoxicillin was at $2.7 \pm 0.2$ minutes, while that of clavulanic acid was $5.0 \pm$ 0.2 minutes (Figure 4).
3.3.2. Amoxicillin Oral Dry Suspension Potency Determination. On day zero, 92.0\% (12 out of 13) of analyzed amoxicillin oral suspension samples met the specified USP limits for content, while on day seven, $85.0 \%$ (11 out of 13 ) of the samples and the control were still within the USP limits. However, $23.1 \%$ (3 out of 13) failed to meet the USP limits for assay as presented in Table 4 and were all imported generic products. They were sampled from South B, South C, and Kibra.

3.3.3. Amoxicillin/Clavulanic Acid Oral Dry Suspension Potency Determination. Immediately after reconstitution (day zero), $75.0 \%$ (9 out of 12) of the samples analyzed complied with USP specifications for assay as indicated in Table 5. All the samples were within compendia limits for 
TABLE 2: Uniformity of weight for amoxicillin/clavulanic acid tablet samples.

\begin{tabular}{|c|c|c|c|c|c|c|c|}
\hline $\begin{array}{l}\text { Sample } \\
\text { code }\end{array}$ & $\begin{array}{l}\text { Country } \\
\text { of origin }\end{array}$ & $\begin{array}{l}\text { Labelled active } \\
\text { ingredients (mg) }\end{array}$ & $\begin{array}{c}\text { Average weight } \\
\text { uniformity }(\mathrm{mg}) \pm \mathrm{SD}\end{array}$ & RSD & $\begin{array}{l}\text { Mean weight } \\
\text { deviation }(\%)\end{array}$ & $\begin{array}{l}\text { Number of tablets } \\
\text { outside USP range }\end{array}$ & $\begin{array}{c}\text { USP-acceptable } \\
\text { criteria }\end{array}$ \\
\hline Control & $\begin{array}{l}\text { United } \\
\text { Kingdom }\end{array}$ & 625 & $1083.9 \pm 9.11$ & 0.8 & $-1.7300 \sim 1.2800$ & 0 & $\pm 5 \%$ \\
\hline KAN95 & India & 375 & $739.7 \pm 9.07$ & 1.2 & $-1.9880 \sim 2.7166$ & 0 & $\pm 5 \%$ \\
\hline SB36 & India & 375 & $784.6 \pm 6.69$ & 0.9 & $-1.7334 \sim 1.2236$ & 0 & $\pm 5 \%$ \\
\hline CBD131 & India & 625 & $1091.0 \pm 14.84$ & 1.4 & $-2.9532 \sim 2.1429$ & 0 & $\pm 5 \%$ \\
\hline KBR90 & India & 625 & $1023.1 \pm 17.89$ & 1.7 & $-3.0920 \sim 2.8506$ & 0 & $\pm 5 \%$ \\
\hline SB57 & India & 625 & $1041.0 \pm 12.10$ & 1.2 & $-3.1586 \sim 1.9424$ & 0 & $\pm 5 \%$ \\
\hline CBD136 & India & 625 & $1051.1 \pm 11.34$ & 1.1 & $-2.2771 \sim 1.6425$ & 0 & $\pm 5 \%$ \\
\hline
\end{tabular}

RSD: relative standard deviation, SD: standard deviation.

TABLE 3: Uniformity of weight for amoxicillin capsule samples.

\begin{tabular}{|c|c|c|c|c|c|c|c|}
\hline $\begin{array}{l}\text { Sample } \\
\text { code }\end{array}$ & $\begin{array}{l}\text { Country } \\
\text { of origin }\end{array}$ & $\begin{array}{l}\text { Labelled active } \\
\text { ingredients (mg) }\end{array}$ & $\begin{array}{c}\text { Average weight } \\
\text { uniformity }(\mathrm{mg}) \pm \mathrm{SD}\end{array}$ & RSD & $\begin{array}{l}\text { Mean weight } \\
\text { deviation (\%) }\end{array}$ & $\begin{array}{c}\text { Number of capsules } \\
\text { outside USP range }\end{array}$ & $\begin{array}{c}\text { USP-acceptable } \\
\text { criteria }\end{array}$ \\
\hline KAY52 & China & 250 & $312.8 \pm 5.31$ & 1.7 & $-1.8862 \sim 3.1969$ & 0 & $\pm 7.5 \%$ \\
\hline SC10 & Kenya & 250 & $288.7 \pm 8.37$ & 2.9 & $-5.2650 \sim 4.8147$ & 0 & $\pm 7.5 \%$ \\
\hline SB32 & India & 250 & $301.9 \pm 6.07$ & 2.0 & $-4.0742 \sim 5.2004$ & 0 & $\pm 7.5 \%$ \\
\hline KAY56 & India & 500 & $594.8 \pm 5.83$ & 1.0 & $-2.1520 \sim 1.9670$ & 0 & $\pm 5.0 \%$ \\
\hline KAY51 & India & 250 & $309.0 \pm 9.96$ & 3.2 & $-8.2201 \sim 6.9579$ & 1 & $\pm 7.5 \%$ \\
\hline ZIM109 & Kenya & 250 & $295.7 \pm 5.59$ & 1.9 & $-3.5171 \sim 4.1258$ & 0 & $\pm 7.5 \%$ \\
\hline CBD138 & Kenya & 250 & $336.6 \pm 10.84$ & 3.2 & $-5.7932 \sim 4.8128$ & 0 & $\pm 7.5 \%$ \\
\hline KBR78 & China & 250 & $300.0 \pm 7.70$ & 2.6 & $-3.2000 \sim 5.000$ & 0 & $\pm 7.5 \%$ \\
\hline KAN120 & $\begin{array}{l}\text { United } \\
\text { Kingdom }\end{array}$ & 500 & $588.6 \pm 6.58$ & 1.1 & $-2.3955 \sim 1.9198$ & 0 & $\pm 5.0 \%$ \\
\hline SC13 & India & 500 & $579.9 \pm 7.75$ & 1.3 & $-2.5349 \sim 2.2935$ & 0 & $\pm 5.0 \%$ \\
\hline SB21 & China & 500 & $585.4 \pm 11.17$ & 1.9 & $-2.6478 \sim 4.0656$ & 0 & $\pm 5.0 \%$ \\
\hline KBR84 & Kenya & 500 & $591.7 \pm 4.49$ & 0.8 & $-2.0788 \sim 1.1323$ & 0 & $\pm 5.0 \%$ \\
\hline KBR87 & India & 250 & $296.9 \pm 6.47$ & 2.2 & $-4.8501 \sim 2.8629$ & 0 & $\pm 7.5 \%$ \\
\hline KBR67 & Kenya & 250 & $436.5 \pm 9.91$ & 2.3 & $-5.0401 \sim 3.3219$ & 0 & $\pm 7.5 \%$ \\
\hline KRN94 & Mexico & 500 & $587.2 \pm 7.38$ & 1.3 & $-0.0249 \sim 0.0189$ & 0 & $\pm 5.0 \%$ \\
\hline KBR77 & Kenya & 500 & $592.5 \pm 8.30$ & 1.4 & $-2.3122 \sim 2.4810$ & 0 & $\pm 5.0 \%$ \\
\hline CBD128 & $\begin{array}{l}\text { United } \\
\text { Kingdom }\end{array}$ & 500 & $589.6 \pm 5.93$ & 1.0 & $-1.3569 \sim 1.7639$ & 0 & $\pm 5.0 \%$ \\
\hline KAY42 & China & 500 & $593.2 \pm 3.77$ & 0.6 & $-1.0115 \sim 1.3823$ & 0 & $\pm 5.0 \%$ \\
\hline SC12 & India & 500 & $589.9 \pm 8.80$ & 1.5 & $-3.9329 \sim 2.9836$ & 0 & $\pm 5.0 \%$ \\
\hline KBR89 & India & 500 & $587.8 \pm 23.99$ & 4.1 & $-10.496 \sim 4.2361$ & 3 & $\pm 5.0 \%$ \\
\hline CBD127 & China & 500 & $587.8 \pm 23.57$ & 4.0 & $-6.822 \sim 9.0167$ & 8 & $\pm 5.0 \%$ \\
\hline KAN101 & India & 500 & $547.6 \pm 29.57$ & 5.4 & $-8.6591 \sim 7.1950$ & 9 & $\pm 5.0 \%$ \\
\hline
\end{tabular}

RSD: relative standard deviation; SD: standard deviation.

clavulanic acid content, while $25.0 \%$ (3 out of 12) of the samples did not meet the limits for amoxicillin content. On day seven, only $33.0 \%$ (4 out of 12 ) of the samples were within specifications for content assay for both active ingredients. Half of the samples $(50.0 \%$; 6 out of 12$)$ were below pharmacopoeial limits for amoxicillin content. Eight out of twelve (66.7\%) sam- ples failed to meet pharmacopoeial specifications and were imported products. Three were sampled from Nairobi Central, 2 from South C, and 3 each from Kibra, Weslands, and Kayole wards. In general, only $56.0 \%$ (14 out of 25 ) of the samples were within the compendia limits for content analysis for both single- and combined-dosage formulation samples. 

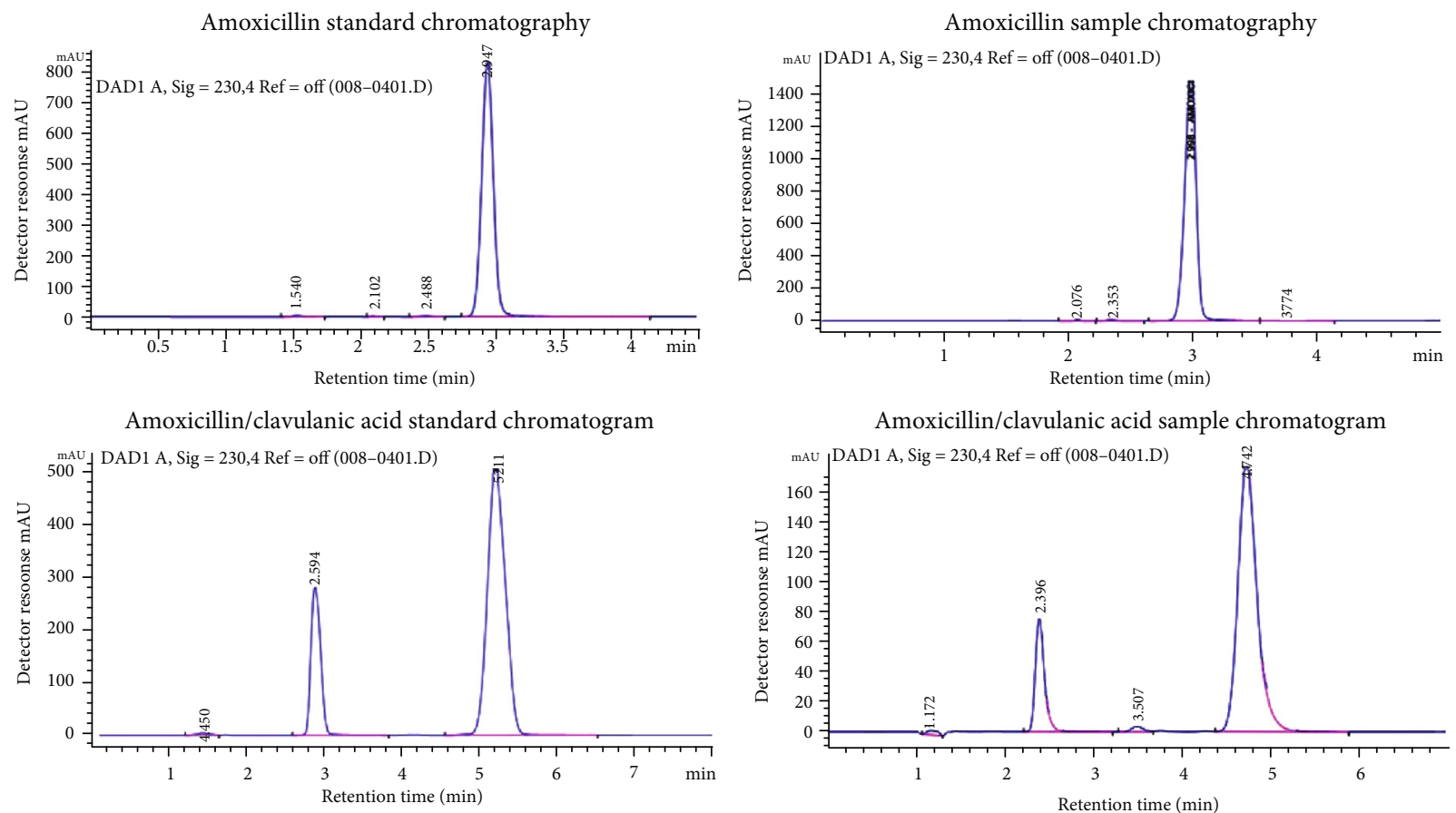

FIgURE 4: Typical chromatograms: (a) amoxicillin standard chromatography, (b) amoxicillin sample chromatography, (c) amoxicillin/clavulanic acid standard chromatogram, (d) amoxicillin/clavulanic acid sample chromatogram. Chromatographic parameters: C18 $4.6 \mu \mathrm{m}$ column; temperature $40^{\circ} \mathrm{C}$; injection volume $10 \mu \mathrm{l}$; flow rate $1.5 \mathrm{ml} / \mathrm{min}$.

TABle 4: Active pharmaceutical ingredient content results for amoxicillin dry oral suspension samples.

\begin{tabular}{|c|c|c|c|c|}
\hline \multirow[t]{2}{*}{ Sample code } & \multirow[t]{2}{*}{ Country of origin } & \multirow{2}{*}{$\begin{array}{c}\text { Labelled active } \\
\text { ingredients }(\mathrm{mg} / 5 \mathrm{ml})\end{array}$} & \multicolumn{2}{|c|}{$\begin{array}{c}\text { Chemical content as \% } \\
\text { label claim (RSD) }\end{array}$} \\
\hline & & & Day 0 & Day 7 \\
\hline Control & United Kingdom & 250 & $93.56(0.26)$ & $90.12(0.63)$ \\
\hline KAN118 & Kenya & 125 & $98.56(1.36)$ & $96.13(0.2)$ \\
\hline KBR63 & India & 125 & $99.56(0.25)$ & $95.48(0.67)$ \\
\hline KBR82 & India & 125 & $101.18(0.96)$ & $96.70(0.19)$ \\
\hline KAY43 & India & 125 & $98.56(0.68)$ & $96.24(0.52)$ \\
\hline KBR83 & Kenya & 125 & $95.60(1.12)$ & $90.11(0.64)$ \\
\hline SC06 & Kenya & 125 & $104.21(0.97)$ & $100.08(1.21)$ \\
\hline ZIM106 & Kenya & 125 & $102.97(0.77)$ & $95.32(0.26)$ \\
\hline ZIM113 & India & 125 & $101.58(0.33)$ & $95.71(0.36)$ \\
\hline KAY54 & United Arab Emirates & 250 & $100.22(0.21)$ & $97.03(1.35)$ \\
\hline SB38 & Kenya & 250 & $103.91(1.05)$ & $96.79(0.33)$ \\
\hline SB19 & Egypt & 125 & $92.81(1.00)$ & $88.27(1.73)$ \\
\hline SC03 & India & 125 & $91.30(1.57)$ & $88.24(0.57)$ \\
\hline KBR74 & India & 125 & $86.02(0.53)$ & $81.20(1.07)$ \\
\hline
\end{tabular}

RSD: relative standard deviation; USP limits: at $90 \%-120 \%$ of label claim.

\subsection{Potency Determination and Dissolution Test for Tablets and Capsules}

3.4.1. Amoxicillin Capsules. All 19 amoxicillin capsule samples analyzed met the specified limits for chemical content while seventeen of nineteen $(89.5 \%)$ complied with the pharmacopoeial specifications for dissolution test as shown in Table 6. Dissolution chemical contents of 2 imported sam- ples were outside the required limits and were sampled from Kayole and South C wards.

3.4.2. Amoxicillin/Clavulanic Acid Tablets. The control and $66.7 \%$ ( 4 out of 6 ) of amoxicillin/clavulanic acid samples analyzed were within the specifications for API content as shown in Table 7. All the samples were within limits for clavulanic acid content while 2 imported samples, each sampled from 
TABLE 5: Active pharmaceutical ingredient content results for amoxicillin/clavulanic acid dry oral suspension samples.

\begin{tabular}{|c|c|c|c|c|c|c|}
\hline \multirow[t]{2}{*}{ Sample code } & \multirow[t]{2}{*}{ Country of origin } & \multirow{2}{*}{$\begin{array}{c}\text { Labelled active } \\
\text { ingredients }(\mathrm{mg} / 5 \mathrm{ml})\end{array}$} & \multicolumn{2}{|c|}{$\begin{array}{l}\text { Chemical content as \% label } \\
\text { claim for clavulanic acid (RSD) }\end{array}$} & \multicolumn{2}{|c|}{$\begin{array}{l}\text { Chemical content as \% label } \\
\text { claim for amoxicillin (RSD) }\end{array}$} \\
\hline & & & Day 0 & Day 7 & Day 0 & Day 7 \\
\hline KAN119 & India & 228 & $112.73(1.78)$ & $100.01(0.84)$ & $108.23(0.94)$ & $102.00(0.20$ \\
\hline KBR60 & United Arab Emirates & 228 & $113.48(0.47)$ & $102.20(0.58)$ & $104.22(0.27)$ & $100.04(0.37$ \\
\hline KRN93 & Canada & 457 & $98.99(0.83)$ & $90.62(0.48)$ & $102.24(0.33)$ & $96.20(0.66)$ \\
\hline SC05 & United Kingdom & 228 & $99.51(0.93)$ & $96.18(0.70)$ & $96.53(0.68)$ & $90.53(0.65)$ \\
\hline WST98 & India & 228 & $101.03(0.23)$ & $96.67(0.48)$ & $91.66(1.83)$ & $86.83(0.80)$ \\
\hline KBR80 & India & 228 & $105.49(1.29)$ & $98.34(0.24)$ & $92.02(1.25)$ & $88.85(1.95)$ \\
\hline CBD132 & India & 228 & $116.93(0.64)$ & $114.64(0.73)$ & $92.54(1.33)$ & $89.12(1.97)$ \\
\hline SC011 & France & 642.9 & $96.50(0.75)$ & $88.91(0.58)$ & $96.90(0.57)$ & $90.75(1.15)$ \\
\hline KAY40 & Jordan & 642.9 & $94.43(0.69)$ & $86.35(0.87)$ & $94.29(0.22)$ & $91.75(0.77)$ \\
\hline SC08 & India & 228 & $101.70(0.28)$ & $96.61(0.21)$ & $82.00(0.93)$ & $80.22(0.30)$ \\
\hline CBD137 & India & 457 & $94.03(1.00)$ & $91.30(1.77)$ & $89.76(0.90)$ & $83.22(1.03)$ \\
\hline CBD133 & India & 228 & $93.43(0.8)$ & $89.93(0.67)$ & $85.12(1.63)$ & $82.07(0.57)$ \\
\hline
\end{tabular}

RSD: relative standard deviation; USP limits: amoxicillin at 90\%-120\% and clavulanic acid at $90 \%-125 \%$ of label claim.

TABLE 6: Active pharmaceutical ingredient and dissolution test results for amoxicillin capsules.

\begin{tabular}{|c|c|c|c|c|}
\hline Sample code & Country of origin & $\begin{array}{c}\text { Labelled active } \\
\text { ingredients (mg) }\end{array}$ & $\begin{array}{c}\text { Chemical content } \\
\text { as \% label claim (RSD) }\end{array}$ & $\begin{array}{l}\text { Dissolution chemical content } \\
\text { as \% label claim (RSD) }\end{array}$ \\
\hline KAY52 & China & 250 & $95.91(0.71)$ & $99(3.71)$ \\
\hline SC10 & Kenya & 250 & $98.24(0.26)$ & $99(1.33)$ \\
\hline SB32 & India & 250 & $93.93(0.27)$ & $97(4.51)$ \\
\hline KAY56 & India & 500 & $97.08(0.34)$ & $97.8(5.3)$ \\
\hline KAY51 & India & 250 & $98.60(0.66)$ & $95(1.8)$ \\
\hline ZIM109 & Kenya & 250 & $95.98(0.29)$ & $94(5.3)$ \\
\hline CBD138 & Kenya & 250 & $98.12(1.92)$ & $93(3.67)$ \\
\hline KBR78 & China & 250 & $94.09(1.12)$ & $92(1.7)$ \\
\hline KAN120 & United Kingdom & 500 & $96.67(0.63)$ & $100(2.52)$ \\
\hline KBR87 & India & 250 & $95.06(0.23)$ & $91.1(5.8)$ \\
\hline SC013 & India & 500 & $94.20(0.95)$ & $90.70(4.30)$ \\
\hline SB021 & China & 500 & $92.60(1.64)$ & $88(1.79)$ \\
\hline KBR67 & Kenya & 250 & $90.74(0.55)$ & $88(5.3)$ \\
\hline KBR84 & Kenya & 500 & $94.34(1.99)$ & $82.1(3.80)$ \\
\hline KRN94 & Mexico & 500 & $91.94(0.54)$ & $82(5.2)$ \\
\hline KBR77 & Kenya & 500 & $94.78(0.11)$ & $82.10(8.3)$ \\
\hline CBD128 & United Kingdom & 500 & $96.57(0.26)$ & $81.4(4.6)$ \\
\hline KAY42 & China & 500 & $94.89(0.62)$ & 76.4(7.5) \\
\hline SC12 & India & 500 & $93.91(0.46)$ & $75.5(7.5)$ \\
\hline
\end{tabular}

RSD: relative standard deviation; USP limits: content determination at $~ 90 \%-120 \%$ and dissolution not less than (NLT) $~ 80 \%$ of label claim.

Nairobi Central and South B wards, did not meet specifications for amoxicillin content, hence they were eliminated from dissolution studies. Only 4 samples and the control were therefore subjected to a dissolution test and only 2 (50\%) met the compendia requirements for dissolution as shown in Table 7.

3.4.3. Summary of Sample Quality from the Same Manufacturer. When comparing samples from the same manufacturers but with different batch numbers, varying results were noted as shown in Table 8.

\section{Discussion}

The magnitude of counterfeit or substandard antibiotics in Kenya has not yet been quantified [19, 33]. However, good quality medicines are essential in management and treatment of diseases and contribute to the achievement of universal 
TABLE 7: Content determination and dissolution test results for amoxicillin/clavulanic acid tablets.

\begin{tabular}{lcccccc}
\hline Sample code & Country of origin & $\begin{array}{c}\text { Labelled active } \\
\text { ingredients (mg) }\end{array}$ & \multicolumn{2}{c}{$\begin{array}{c}\text { Chemical content as \% } \\
\text { label claim (RSD) }\end{array}$} & \multicolumn{2}{c}{$\begin{array}{c}\text { Dissolution chemical content } \\
\text { as \% label claim (RSD) } \\
\text { Amoxicillin }\end{array}$} \\
\hline Control & United Kingdom & 625 & $94.00(0.99)$ & $95.00(1.46)$ & $101(1.44)$ & $94.00(0.76)$ \\
KAN95 & India & 375 & $99.82(0.59)$ & $93.13(0.29)$ & $88.70(3.40)$ & $97.40(2.80)$ \\
SB36 & India & 375 & $115.57(1.37)$ & $87.81(1.24)$ & ND & ND \\
CBD131 & India & 625 & $105.81(0.35)$ & $99.84(0.39)$ & $77.60(7.90)$ & $88.10(8.6)$ \\
KBR90 & India & 625 & $97.80(0.50)$ & $93.40(0.44)$ & $75.2(1.61)$ & $77.50(1.97)$ \\
SB57 & India & 625 & $98.04(1.19)$ & $92.13(0.31)$ & $88.0(4.80)$ & $87.60(4.20)$ \\
CBD136 & India & 625 & $113.00(1.28)$ & $84.81(1.60)$ & ND & ND \\
\hline
\end{tabular}

RSD: relative standard deviation; USP limits: content determination for amoxicillin at 90\%-120\% and clavulanic acid at 90\%-125\% of label claim. Dissolution: NLT $85 \%$ for amoxicillin and NLT 80\% for clavulanic acid of label claim; ND: not done.

TABLE 8: Summary of content determination and dissolution test for samples from the same manufacturers but differing in quality.

\begin{tabular}{|c|c|c|c|c|c|}
\hline \multirow{2}{*}{ Sample code } & \multirow{2}{*}{ Origin } & \multirow{2}{*}{ Sample type } & \multirow{2}{*}{$\begin{array}{c}\text { Labelled active } \\
\text { ingredients }(\mathrm{mg})\end{array}$} & \multicolumn{2}{|c|}{ Summary } \\
\hline & & & & Potency determination & Dissolution test \\
\hline KAY56 & \multirow{4}{*}{ India } & Capsule & 500 & Complied & Complied \\
\hline KAY43 & & Amoxicillin oral suspension & 125 & Complied & N/A \\
\hline KAN95 & & Amoxicillin/clavulanic acid tablets & 375 & Complied & Complied \\
\hline CBD133 & & Amoxicillin/clavulanic acid oral suspension & 228 & Failed & N/A \\
\hline KBR63 & \multirow{2}{*}{ India } & Amoxicillin oral suspension & 125 & Complied & N/A \\
\hline SC08 & & Amoxicillin/clavulanic acid oral suspension & 228 & Failed & N/A \\
\hline KAY42 & \multirow{2}{*}{ China } & Capsule & 500 & Complied & Failed \\
\hline KAY52 & & Capsule & 250 & Complied & Complied \\
\hline KRN93 & Canada & Amoxicillin/clavulanic acid oral suspension & 457 & Complied & N/A \\
\hline SC03 & India & Amoxicillin oral suspension & 125 & Failed & N/A \\
\hline CBD128 & New Zealand & Capsule & 500 & Complied & Complied \\
\hline SC13 & France & Capsule & 500 & Complied & Complied \\
\hline KRN94 & Mexico & Capsule & 500 & Complied & Complied \\
\hline
\end{tabular}

N/A: not applicable.

health coverage (UHC). This study established that amoxicillin was commonly stocked in pharmacies within Nairobi County. This concurs with the WHO Expert Committee [34] report on essential medicines that recommends amoxicillin as a drug with lower potential for resistance and should be readily accessible for the treatment of a wide range of common bacterial infections. In addition, innovator and generic amoxicillin drugs in the Kenyan market are largely imports at $85.2 \%$. Further noted was that all the locally manufactured drugs $(14.8 \%)$ in the market were a single molecule of amoxicillin while all the combination clavulanic/amoxicillin acid products $(100 \%)$ were imports. A report on prices and availability of medicines in the Kenyan market similarly noted that predominantly imported generics were from India and China [23]. A total of 106 different brands were found in the market of which only 21 (19.8\%) were locally manufactured; however, there could be more brands that were not captured. Studies have shown that having too many brands of the same molecule poses challenges in ensuring quality to the regulatory body $[23,35]$. Most of the pharmacies stocked (99.6\%) innovator brands of single-molecule amoxicillin $\left(\right.$ Amoxil $\left.^{\circledR}\right)$ and its combination amoxicillin and clavulanic acid (Augmentin ${ }^{\circledR}$ ). Comparable findings were reported in a survey on the medicine pricing in Kenya which noted that innovator brands were mostly sold in Nairobi, with availability being twice more likely than in other regions in Kenya [36]. Nairobi Central and Westlands wards had the highest stocked brands of both innovator and generic products (Figure 3). According to the Ministry of Health [37], these two wards were reported to host most pharmaceutical distributor outlets and pharmacies.

Uniformity of weight was employed as a good pointer to Good Manufacturing Practice (GMP). This assures the drug content in each unit dose is evenly distributed in a normal range around the labelled active ingredient. Weight variation vividly reflects on the content of the active ingredient [38]. All the amoxicillin/clavulanic acid tablet samples met the compendia specification for uniformity of weight (Table 2). These results agreed with a previous study done in Ethiopia [39].

Amoxicillin capsules, however, recorded a failure rate of $13.6 \%$ as shown in Table 3. Related results were reported in a study done in Nigeria on amoxicillin capsules 
in which $30 \%$ of the samples analyzed failed to comply [40]. Once such weight variances are observed, it is thereafter impossible to assure the active ingredient content of the drug units [41, 42]. It is for this reason that the brands which failed the weight uniformity test were eliminated from subsequent tests.

All samples analyzed displayed retention times orresponding with that of the respective standards. This confirmed that all samples contained the targeted API [43].

Potency determination is critical for quality assessment of active pharmaceutical content. Appropriate content is important in attaining effective concentration at the site of infections when administered [44, 45]. Oral suspensions of amoxicillin are available in the market as dry powders for reconstitution and should be refrigerated thereafter to prevent degradation of active ingredients. However, most households do not own refrigerators and hence store these drugs at room temperature. Studies have reported that the penetration level of refrigeration appliances in Nairobi is at 35\% majorly in high- and middle-income level households [46]. Dry oral suspensions should be within the recommended compendia specifications immediately after reconstitution and seven days after for both amoxicillin and clavulanic acid contents [32]. Substantial variations could result in ineffective or toxic therapeutic drug levels [47].

Out of the thirteen amoxicillin dry oral suspension samples analyzed, $23.1 \%$ presented values below compendia requirements on the seventh day (Table 4). This is consistent with the findings of Taylor et al. [48] that reported low API quantities in $40 \%$ of amoxicillin oral dry suspensions analyzed. Similar results were also documented in Saudi Arabia where $8 \%$ on day zero and $38 \%$ on day seven of amoxicillin oral dry suspensions analyzed were below pharmacopoeial limits [49].

Twenty-five percent of amoxicillin/clavulanic acid oral dry suspensions were below compendia limits for amoxicillin on day zero but were within the limits for clavulanic acid (Table 5), while by day seven an additional 5 samples were below pharmacopoeial specification limits [30] resulting in a $66.7 \%$ (8 out of 12) failure rate. This shows lack of stability of the drugs over the prescription period as significant degradation was noted by the seventh day of use especially for the amoxicillin and clavulanic acid combination. This implies that the patient will receive suboptimal dosages during the latter treatment stages thus resulting to induction of resistance in the target bacteria or host toxicity from degradation products [50]. Nettey et al. [51] reported comparable findings in Ghana with amoxicillin content showing more failure than clavulanic acid.

All the nineteen amoxicillin capsule samples met the pharmacopoeial specifications for potency determination (Table 6) [30]. Related results were reported in Ethiopia [52] and in a study on quality of antibiotics in Ghana, Nigeria, and the United Kingdom where 95\% of amoxicillin capsules analyzed complied with the specified tolerance limits [53]. On the contrary, a study conducted in India on generic amoxicillin capsules bought from open market vendors recorded $28.3 \%$ of the products outside the specifications [54]. Nguyo et al., (2013) similarly reported 50.0\% noncom- pliance of locally manufactured amoxicillin capsules analyzed from 2006 to 2010 .

In this study, $66.7 \%$ of amoxicillin/clavulanic acid tablets investigated were within the specifications for API content (Table 7). Contrasting results were stated in Ghana where all amoxicillin/clavulanic acid samples analyzed were outside required limits [51], while in Nigeria and Ethiopia, Olanrewaju et al. [55] and Mekonnen et al. [39], respectively, reported compliance with compendia limits for all amoxicillin/clavulanic acid tablet samples investigated. Many factors such as storage conditions, transportation during distribution, components of drug composition, and nature of the active ingredient used during formulation may affect the content of a drug $[4,56,57]$.

Dissolution is the primary quality control test to determine whether a drug product can release its active pharmaceutical ingredient(s) in a timely manner. It is associated to drug bioavailability and thus drug absorption $[58,59]$. It is therefore used to assess batch-to-batch quality and provide process control and quality assurance under optimal operating conditions. Hence, significant variations in the dissolution rate among the same products indicate inconsistencies in the drug formulation and delivery process [60]. According to the USP, the amount of amoxicillin released within 60 minutes for amoxicillin capsules and 30 minutes for amoxicillin/clavulanic acid tablets should not be less than $80 \%$ and $85 \%$, respectively, while that of clavulanic acid should not be less than $80 \%$ of the labelled claim [30]. Majority (89.5\%) of the amoxicillin capsules investigated complied with pharmacopoeial specifications (Table 6). Contrary results were observed in Ghana, Nigeria, and United Kingdom, where Kaur et al. [53] reported compliance with pharmacopoeial requirements of all amoxicillin capsules tested in a study on antibiotics. Only $50 \%$ of amoxicillin/clavulanic acid tablets met the specified limits for dissolution. This was inconsistent with studies done by Olanrewaju et al. [55] in Nigeria that reported $86 \%$ compliance and with studies done by Nettey et al. [51] in Ghana that reported 93\% of amoxicillin/clavulanic acid tablets tested complied with pharmacopoeial specifications.

The presence of poor-quality amoxicillin products was recorded in $70 \%$ (7 out of 10) of wards sampled, with Nairobi Central having the highest percentage. This could be because it hosts the central business district and has the highest number of pharmacies, hence it is easy for poor-quality drugs to infiltrate the market [24]. The Kibra ward similarly recorded a significant percentage of substandard drugs with most pharmacies stocking mainly generic products. Kibra hosts Africa's largest urban slum and most of its dwellers can only afford cheaper drugs and can be easily sold poor-quality drugs by unscrupulous dealers [25].

Overall, $37.7 \%$ (20 out of 53) of the samples analyzed were of poor quality as per the USP specifications and were all imported products. Hence, this is an indication that more stringent measures should be taken to ensure that imports comply with quality requirements. Samples from Nairobi Central had the highest substandard prevalence at $11.3 \%$, followed by Kibra and South C at 7.5\%, South B and Kayole at $3.8 \%$, and Kangemi and Westlands at $1.9 \%$ each. There was no relationship between socio-economical setting and 
product quality as seven out of the ten wards (70.0\%) sampled registered the presence of substandard medicines.

Findings in Table 8 show samples from the same manufacturer having varying quality. This is an indication of nonadherence to GMP by some manufacturers, hence leading to batch-to-batch inconsistency [61]. GMP is part of quality assurance that ensures products are consistently manufactured and controlled to the quality standards appropriate to their intended use and as required by the regulating authority [62]. Inconsistency in manufacturing processes increases risks inherent to pharmaceutical production such as cross-contaminations, poor inprocess controls, inappropriate packaging and labeling, and poor storage and transportation processes. This consequently results in substandard and/or counterfeit pharmaceutical products.

\section{Limitations}

Registration status of the various brands of amoxicillin formulations were not confirmed from the official regulator (PPB). Only identification, content determination, uniformity, and dissolution tests were done. Therefore, "quality" in this study refers only to the uniformity of weight of solid dosages, content analysis, and dissolution of the active ingredient in terms of the ranges specified by the USP. Some samples met compendia limits for content analysis and dissolution, while other samples from the same manufacturers failed. It was assumed that this was due to poor manufacturing practices and did not consider degradation of the samples due to poor storage and transportation processes.

\section{Conclusion}

The results from this study shows that some amoxicillin formulations marketed in Nairobi County are of poor quality. Generally, $37.7 \%$ of the samples analyzed failed to meet the pharmacopoeial specifications and were all imported products. This observation goes against the perception that imported compared to locally manufactured medicines in developing countries are of better quality. Poor-quality amoxicillin formulations were documented in 70\% (7 out of 10) of the sampled wards, hence there was no correlation between socioeconomical setting and drug quality. Therefore, there is a need to extend the study to other counties to inform on the situation of antibiotic quality in the Kenyan market. Strict regulation is also essential to guarantee compliance with good manufacturing practices by pharmaceutical manufacturers. Ensuring availability of quality essential medicines to the public through frequent postmarket surveillance is an important contribution in the fight against antimicrobial resistance and reduction in disease burden through mitigating treatment failures. This will contribute towards the achievement of universal health coverage as a key target under the United Nations sustainable development goals which Kenya hopes to achieve by 2030 .

\section{Data Availability}

The authors confirm that the data supporting the findings of this study are included within this published article.

\section{Conflicts of Interest}

The authors declare no conflicts of interest regarding publication of this manuscript whatsoever.

\section{Acknowledgments}

The authors are grateful to the Kenya Medical Research Institute-IRG for funding this work (KEMRI/CONF/FIN/6/101/Vol. II). The authors would also like to sincerely thank Kenyatta University, Dawa Limited, and National Quality Control Laboratory (NQCL) for their support, as well as the Director General of Kenya Medical Research Institute for providing an enabling environment for this work to be done.

\section{References}

[1] HealthTech Report, Prevalence of counterfeit and substandard antibiotics in developing countries, PATH, Seattle, Washington, 2014

[2] B. Berkrot, Fake pharmaceuticals. Bad medicine. The world's drug supply is global. Governments have failed to keep up, The Economist, New York, 2012, https://www.reuters.com/ article/us-avastin-drug-fake-idUSBRE82B0YY20120312.

[3] E. Blackstone, J. Fuhr, and S. Pociask, "The health and economic effects of counterfeit drugs," American Health and Drug Benefits, vol. 7, no. 4, pp. 216-224, 2014.

[4] A. Johnston and D. Holt, "Substandard drugs: a potential crisis for public health," British Journal of Clinical Pharmacology, vol. 78, no. 2, pp. 218-243, 2014.

[5] K. Mwambete, "Antibacterial quality of some antibiotics available in five administrative areas along the national borders of Tanzania," Integrated Pharmacy Research and Practice, vol. 3, no. 4, pp. 97-107, 2014.

[6] A. Delepierre, A. Gayot, and A. Carpentier, "Update on counterfeit antibiotics worldwide; public health risks," Médecine et Maladies Infectieuses, vol. 42, no. 6, pp. 247-255, 2012.

[7] I. Kibwage, "Counterfeiting of drugs and the necessity of quality control systems in developing countries," Master of Cultures and Development Studies (CADES), vol. 3, no. 4, pp. 112, 2008.

[8] C. Hubschwerlen, " $\beta$-Lactam antibiotics," in Comprehensive Medicinal Chemistry II, pp. 479-518, Elsevier, 2007.

[9] B. Thakuria and K. Lahon, "The beta lactam antibiotics as an empirical therapy in a developing country: an update on their current status and recommendations to counter the resistance against them," Journal of Clinical and Diagnostic Research, vol. 7, no. 6, pp. 1207-1214, 2013.

[10] T. Silhavy, D. Kahne, and S. Walker, "The bacterial cell envelope," Cold Spring Harbor Perspectives in Biology, vol. 2, no. 5, pp. 414-417, 2010.

[11] C. Kaye, "The clinical pharmacokinetics of a new pharmacokinetically enhanced formulation of amoxicillin/clavulanate," Clinical Therapeutics, vol. 23, no. 4, pp. 578-584, 2001.

[12] P. Saudagar, S. Survase, and R. Singhal, "Clavulanic acid: a review," Biotechnology Advances, vol. 26, no. 4, pp. 335-351, 2008.

[13] P. Lukulay, "Fake drugs flooding poor African markets," 2016, July 2016, http://www.the-star.co.ke/news/2016/02/11/fakedrugs-flooding-poor-african-markets_c1292641. 
[14] R. Philippa, “"Lab on a Card” spots poor quality drugs that can kill," 2015, July 2016, http://www.bbc.co.uk/news/health32938075.

[15] J. Sambira, Counterfeit Drugs Raise Africa's Temperature, UN Africa Renewal, 2013, http://www.un.org/africarenewal/ magazine/may-2013/counterfeit-drugs-raise-africa'stemperature.

[16] G. Gatonye, Fake drugs killing Kenyans as traders smile to the bank: Kenya, Standard Digital, Nairobi, Kenya, 2018, https:// www.standardmedia.co.ke/health/article/2001286166/howbad-medicine-is-killing-kenyans.

[17] G. Kajilwa, Poor quality of drugs blamed for undermining the fight against malaria: Kenya, The Standard, Nairobi, Kenya, 2018, https://www.standardmedia.co.ke/article/2001278282/ poor-quality-of-drugs-blamed-for-undermining-the-fightagainst-malaria.

[18] E. Mareb, Killing you slowly: inside Kenya's fake drug scourgeDaily Nation, Daily Nation, Nairobi, Kenya, 2017, https://www .nation.co.ke/health/Inside-Kenya-fake-drug-scourge/ 3476990-3997826-aci8bk/index.html.

[19] Nation Team, Kenya: poor people likely to buy fake drugs, reveals survey, Daily Nation, Nairobi, 2016, http://allafrica .com/stories/201602111347.html.

[20] K. Abuga, J. Nguyo, B. Amugune et al., "Quality of Antiretroviral Drugs Analyzed in the Drug Analysis and Research Unit During 2000-200," East and Central African Journal of Pharmaceutical Sciences, vol. 16, no. 2, pp. 33-43, 2013.

[21] F. Kamau, G. Thoithi, J. Ngugi, O. Kingondu, and I. Kibwage, "Quality of amoxycillin preparations in the Kenyan market," East Central Africa Journal of Pharmaceutical Science, vol. 6, no. 3, pp. 57-60, 2003.

[22] F. Wafula, A. Dolinger, B. Daniels et al., "Examining the quality of medicines at Kenyan healthcare facilities: a validation of an alternative post-market surveillance model that uses standardized patients," Drugs-Real World Outcomes, vol. 4, no. 1, pp. 53-63, 2017.

[23] M. Ewen and D. Okemo, "Prices and availability of locally produced and imported medicines in Kenya," Health Action International, vol. 4, no. 1, pp. 1-23, 2018.

[24] R. Simonetti, N. Clark, and W. Wamae, "Pharmaceuticals in Kenya: the evolution of technological capabilities," in Making Medicines in Africa, International Political Economy Series, M. Mackintosh, G. Banda, P. Tibandebage, and W. Wamae, Eds., pp. 25-44, Palgrave Macmillan UK, London, 2016.

[25] NCPD, The Kenya Population Situation Analysis, National Council for Population and Development, Nairobi, Kenya, 2013, http:// countryeconomy.com/demography/population/kenya.

[26] D. Atemi, "List of Nairobi County wards," Nairobi, Kenya, 2020, 2020, map, scale 0-19, 200 Metres.

[27] World Bank Group, Decision meeting draft: Republic of Kenya country social analysis, Nairobi., 2006http://siteresources .worldbank.org/BOLIVIA/Resources/Republic_of_KenyaCSA.pdf.

[28] World Bank Group, Kenya Economic Update: Policy Options to Advance the Big 4, Nairobi, Kenya, 2018.

[29] D. Morgan and R. Krejcie, Sample size determination using Krejcie and Morgan table, Kenya Projects Organization (KENPRO), 1970.

[30] USP40-NF35 I United States Pharmacopeial Convention, "United States Pharmacopoeia 40-national formulary 35," in U.S. Pharmacopoeia, vol. 2, pp. 2787-2792, U.S. Pharmacopoeia-National Formulary, Rockville, Md, 2017.

[31] P. Kumar Sahu, "Definition of system suitability test limits on the basis of robustness test results," Journal of Analytical \& Bioanalytical Techniques, vol. 8, no. 3, pp. 1-7, 2017.

[32] USP40-NF35 I United States Pharmacopeial Convention, "USP-NF general chapters," in U.S. Pharmacopoeia; General Chapters, U.S. Pharmacopoeia-National Formulary, Rockville, Md, 2017, https://www.usp.org/compounding/compoundinggeneral-chapters.

[33] GARP, Situation analysis and recommendations: antibiotic use and resistance in Kenya, Center for Disease Dynamics, Economics \& Policy, Washington, DC and New Delhi, 2011, https://www.cddep.org/sites/default/files/garp/sitan/pdf/garpkenya.pdf.

[34] WHO Expert Committee, The selection and use of essential medicines: report of the WHO Expert Committee, Geneva, 2017https://apps.who.int/iris/bitstream/handle/10665/ $259481 / 9789241210157$-eng.pdf; j sessionid= 968991504C11670BF9065C85C2A7EB19? sequence $=1$.

[35] B. K. Njue, "Drug regulation in Kenya," Drugs for Neglected Diseases Initiative-DNDi, no. 2, pp. 1-4, 2014.

[36] HAI, and WHO, "A survey medicine prices in Kenya-2004," 2004, http://apps.who.int/medicinedocs/documents/ s18710en/s18710en.pdf.

[37] Ministry of Health, "Republic of Kenya. Kenya Essential Medicines List 2016 Ministry of Health, Nairobi," 2016, http://apps .who.int/medicinedocs/documents/s23035en/s23035en.pdf.

[38] M. Shabana, "A review on the quality control analysis of oral dosage form: tablets," Research \& Reviews: Journal of Pharmacy and Pharmaceutical Sciences, vol. 5, no. 2, pp. 288-292, 2016.

[39] T. Mekonnen, W. Kahaliw, and J. Somasundaram, "In-vitro quality evaluation of different products of amoxicillinclavulanate potassium tablets," International Journal of Allied Medical Sciences and Clinical Research, vol. 4, no. 1, pp. 1016, 2016.

[40] A. J. Obarisiagbon, O. P. Ogunlowo, and F. Agamah, “Comparative study of the physical characteristics of some commercially available brands of amoxicillin capsules," British Journal of Pharmaceutical Research, vol. 5, no. 5, pp. 359-369, 2015.

[41] E. Brochmann-Hanssen and J. Medina, "Dosage variation in tablets," Journal of Pharmaceutical Sciences, vol. 52, no. 7, pp. 630-633, 1963.

[42] S. Zhigang, Y. Naiqi, C. Richard, and S. Florence, "Particle size specifications for solid oral dosage forms: a regulatory perspective," American Pharmaceutical Review, vol. 13, no. 4, pp. 6873, 2010.

[43] S. Moldoveanu, V. David, S. Moldoveanu, and V. David, "Parameters that characterize HPLC analysis," in Essentials in Modern HPLC Separations, pp. 53-83, Elsevier, 2013.

[44] T. Almuzaini, I. Choonara, and H. Sammons, "Substandard and counterfeit medicines: a systematic review of the literature," British Medical Journal Open, vol. 3, no. 8, article e002923, 2013.

[45] M. Butler, M. Blaskovich, and M. Cooper, "Antibiotics in the clinical pipeline in 2013," The Journal of Antibiotics, vol. 66, no. 10, pp. 571-591, 2013.

[46] M. K. Nzia, "End use based model for residential power consumption forecasting in Nairobi Region, Kenya," 2013, http://erepository.uonbi.ac.ke/handle/11295/55748. 
[47] WHO, WHO Medicines Quality Assurance, WHO, 2018, https://www.who.int/medicines/areas/quality_safety/quality_ assurance/en/.

[48] R. Taylor, O. Shakoor, R. Behrens et al., "Pharmacopoeial quality of drugs supplied by Nigerian pharmacies," The Lancet, vol. 357, no. 9272, pp. 1933-1936, 2001.

[49] S. Kyriacos, M. Mroueh, R. Chahine, and O. Khouzam, "Quality of amoxicillin formulations in some Arab countries," Journal of Clinical Pharmacy and Therapeutics, vol. 33, no. 4, pp. 375-379, 2008.

[50] S. Ozawa, D. R. Evans, S. Bessias et al., "Prevalence and estimated economic burden of substandard and falsified medicines in low- and middle-income countries: a systematic review and meta-analysis," The Journal of the American Medical Association Network Open, vol. 1, no. 4, article e181662, 2018.

[51] H. Nettey, G. Allotey-Babington, P. Debrah et al., "The quality and in vitro efficacy of amoxicillin/clavulanic acid formulations in the central region of ghana," Pharmacology \& Pharmacy, vol. 5, no. 1, pp. 49-60, 2014.

[52] W. Mikre and N. Mekonnen, "Quality and influence of tropical storage conditions on amoxicillin formulations marketed in Ethiopia," Journal of Pharmaceutical and Allied Sciences, vol. 3, no. 2, pp. 82-86, 2009.

[53] H. Kaur, M. Lalani, N. Mailk, I. Fadeyi, and A. Van Wyk, "Quality of the antibiotics-amoxicillin and co-trimoxazole from Ghana, Nigeria, and the United Kingdom," The American Journal of Tropical Medicine and Hygiene, vol. 92, no. 6, pp. 87-94, 2015.

[54] A. Khan, R. Khar, and M. Udayabanu, "Quality and affordability of amoxicillin generic products: a patient concern," International Journal of Pharmacy and Pharmaceutical Sciences, vol. 8, no. 1, pp. 386-390, 2015.

[55] O. Olanrewaju, A. Paul, and A. Olusola, "Quality assessment of amoxicillin-clavulanate potassium tablets in Lagos, Nigeria," Journal of Chemical and Pharmaceutical Research, vol. 4, no. 12, pp. 5032-5038, 2012.

[56] F. Al-kershi, G. Othman, and F. Al-qadasi, "Research article quality and stability of amoxicillin-potassium clavulanate drugs marketed in Yemen: influence of tropical storage conditions," vol. 8, no. 6, pp. 160-166, 2016.

[57] N. Peace, O. Olubukola, and A. Moshood, "Stability of reconstituted amoxicillin clavulanate potassium under simulated inhome storage conditions," Journal of Applied Pharmaceutical Science, vol. 2, no. 1, pp. 28-31, 2012.

[58] N. Shahrin, "Solubility and dissolution of drug product: a review," International Journal of Pharmaceutical and Life Sciences, vol. 2, no. 1, pp. 33-41, 2013.

[59] B. Shekunov and E. Montgomery, "Theoretical analysis of drug dissolution: I. Solubility and intrinsic dissolution rate," Journal of Pharmaceutical Sciences, vol. 105, no. 9, pp. 2685-2697, 2016.

[60] V. P. Shah, "Progressive applications of dissolution, its impact, and implications in the pharmaceutical world," Journal of Pharmaceutical Sciences, vol. 102, no. 9, pp. 2895-2897, 2013.

[61] J. Orwa, L. Keter, S. Ouko, I. Kibwage, and G. Rukunga, "Quality of some pharmaceutical products manufactured in Kenya," Pharmaceutical Journal of Kenya, vol. 18, no. 9, pp. 70-71, 2008.

[62] World Health Organization, Quality Assurance of Pharmaceuticals. A Compendium of Guidelines and Related Materials, Geneva, Switzerland, 2007https://www.who.int/medicines/ a reas / quality_safety/quality_as surance/ QualityAssurancePharmVol2.pdf. 